\title{
Long-term trends in the incidence, treatment, hospital fatality and subsequent mortality from acute myocardial infarction in the Czech Republic
}

\author{
Jan Bruthans ${ }^{\mathrm{a}, \mathrm{b}}$, Otto Mayer ${ }^{\mathrm{b}}$, Jiri Jarkovskyc, Miroslav Zvolsky ${ }^{\mathrm{d}}$, Jan Bruthans jre
}

\begin{abstract}
Aims. Studies on the incidence, acute and subsequent mortality from myocardial infarction are limited mostly to selected clinical cohorts and populations and cover relatively short periods. Our aim was to describe and analyse long-term trends on a national scale.

Methods. Acute myocardial infarction (AMI) was defined by the International Classification of Diseases (ICD)10; codes I21 and I22. Our natiowide 1994-2016 data on AMI mortality were obtained from the official mortality statistics (Czech Bureau of Statistics), data on morbidity (hospitalizations) from the National Register of Hospitalizations (Institute for Health Information and Statistics). For further analyses, data from the Czech EUROASPIRE I-V and Czech IMPACT studies were used.

Results. Over the 1994-2016 period the total number of AMI cases per year decreased from 34,084 to 19,015, that of patients hospitalized for AMI from 22,373 to 15,419, the total number of deaths due to AMI from 14,834 to 4,673, in those treated because of AMI from 3,794 to 1,137, and hospital fatality in patients treated for AMI decreased from $17 \%$ to $7.5 \%$. Over the years 1997-2016, the one-year all-cause mortality rate after AMI declined from 25.1 to $17.9 \%$, cardiovascular (CV) mortality from 22.3 to $14.2 \%$, five-year all-cause mortality from 41.7 to $34 \%$, and CV mortality from 34.1 to $23.6 \%$. Conclusion. The Czech Republic has witnessed a pronounced decrease in AMI incidence and fatality and, consequently, long-term mortality. The decreasing incidence and improving course of AMI are due to progress in primary prevention, in acute coronary care and interventional cardiology, and in secondary coronary heart disease (CHD) prevention.
\end{abstract}

Key words: acute myocardial infarction, AMI incidence and fatality trends, post-AMI mortality trends, AMI intervention and treatmen, primary and secondary prevention of AMI

Received: January 6, 2020; Revised: March 12, 2020; Accepted: March 16, 2020; Available online: April, 6, 2020

https://doi.org/10.5507/bp.2020.014

(c) 2021 The Authors; https://creativecommons.org/licenses/by/4.0/

${ }^{a}$ Centre for Cardiovascular Prevention, 1st Faculty of Medicine, Charles University in Prague and Thomayer Hospital, Prague, Czech Republic ${ }^{b}$ 2nd Department of Medicine, Faculty of Medicine Pilsen, Charles University and Faculty Hospital, Pilsen, Pilsen, Czech Republic 'Institute of Biostatistics and Analyses, Faculty of Medicine, Masaryk University, Brno, Czech Republic

'Institute of Medical Information and Statistics of the Czech Republic, Prague, Czech Republic

eDepartment of Biomedical Technology, Faculty of Biomedical Engineering, Czech Technical University, Prague, Czech Republic.

Corresponding author: Jan Bruthans, e-mail:jan.bruthans@seznam.cz

\section{INTRODUCTION}

In the Czech Republic, the decrease in cardiovascular (CV), and coronary heart disease (CHD) mortality in particular, started after 1990 (the year of transition from a totalitarian regime to a democratic society), considerably later than the decline in the USA or Western Europe. Importantly, the decrease in CV mortality has been a continuous and intensive one. The decrease in CHD mortality was driven by declining mortality rates from acute forms of CHD. However, mortality for chronic CHD (I25) stopped declining after 2000 to even increase slightly in the ensuing years, while that from acute forms of CHD continued to decrease at a slower pace ${ }^{1}$.

We felt that an all-round analysis of long-term trends in the incidence, treatment, hospital fatality and subsequent mortalityand recurrenceof acute myocardial infarction (AMI) in the Czech Republic, one of the countries of Central and Eastern Europe that has undergone major political and social changes, might be useful. No studies analysing long-term trends on a nation wide scale and in its complexity in the countries in transition have been published to date.

Studies analysing the long-term trends in the incidence of and mortality from AMI in other countries have been, with some exceptions ${ }^{2-5}$, restricted to shorter time periods, selected subpopulations or AMI subtypes, or have presented earlier data $\mathrm{at}^{6-14}$. While trends in AMI prevalence, hospitalizations and mortality in the Czech Republic up to 2010 were published ${ }^{15-17}$, long-term trends in survival after AMI have not been analysed and described yet.

New treatments and their outcomes, also of acute CHD, are based on clinical studies, but these are carried out in selected populations, limited in time and cannot provide data on morbidity and mortality in large populations, hence knowledge of trends in these statistics and identification of contributing factors on a population-wide scale is obviously useful. 


\section{METHODS}

\section{Data sources and study population}

Acute myocardial infarction was defined according to the International Classification of Diseases (ICD)-10; codes I21 and I22. In clinical practice, the diagnosis was based on specific pain, dynamic changes of ECG consistent with the diagnosis of AMI and increased levels of biomarkers, initially muscle-brain-type creatine kinase replaced in about the year 2005 , by the more precise temporal analyses of troponin T/I ( ref. $^{18}$ ). On the other hand, the number of autopsies in the Czech Republic decreased in that period, which may make the post-mortem diagnoses less accurate. Our nationwide data (current population of 10.6 million) on AMI mortality were obtained from the National Register of Causes of Deaths of the Czech Bureau of Statistics; the register is based on death certificates. Morbidity data were obtained from the National Register of Hospitalizations, a population-wide register collecting data on individuals admitted for stationary hospital treatment (Institute of Medical Information and Statistics of the Czech Republic. For each year of our study, spanning the 1994-2016 period, index hospitalizations for AMI and deaths on AMI were analysed and calculated. For the purpose of our study, nationwide data on coronary revascularization procedures were obtained from the National Register of Cardiac Surgery Procedures and Cardiovascular Interventions receiving data from cardiovascular intervention centres and departments of cardiac surgery.

Regarding patients hospitalized for AMI, we acquired data on their rehospitalizations and, possibly, later death. In our analysis of long-term survival after AMI, the time from the beginning of first hospitalization for AMI to the date of death or to the end of the year 2016 was used to evaluate the 20-year period from 1997 to 2016, with data covering the 1994-1996 period used for verification of hospitalization history and in an effort to minimize any potential bias due to inclusion of patients who had been already hospitalized before the analysed period.

In our analysis, reinfarction was defined as hospitalization for AMI occurring not earlier than 30 days after the end of a preceding hospitalization for AMI. This was because our underlying data did not allow us to determine whether the subsequent hospitalization involved transfer of a patient or admission for a new AMI, so the 30-day period should eliminate most of the patient transfers to another hospital and prevent their inclusion among reinfarctions.

For analyses of secondary prevention of AMI, we used data from the Czech EUROASPIRE I-V studies, which are five independent cross-sectional descriptive surveys of patients examined six months to two years after hospitalization for acute coronary syndrome and/or coronary revascularization, and undertaken in 1995-1996, 19992000, 2006-2007, 2012-2013 and 2016-2017 as part of a European project ${ }^{19}$. For analyses of the impact of risk factors and medication changes on CHD mortality decrease, the results of the Czech IMPACT Study, based on calculations developed by British authors, were used ${ }^{20}$.

\section{Statistical analysis}

For data on the incidence and fatality of AMI, descriptive statistics of trends was used. When analysing subsequent and long-term mortality after AMI, mortality rates were assessed using the cumulative incidence method. The values were standardized by age to eliminate any potential bias due to the aging of the Czech population.

\section{RESULTS}

\section{Trends in AMI incidence and hospitalizations}

To calculate the number of AMI within a current year, we used the number of registered hospitalized persons, based on each patient's personal identity code. By adding to the number of persons hospitalized for AMI that of all those deceased for AMI minus those deceased during hospital treatment for AMI, we calculated the total number (incidence) of AMI in the respective year. The incidence of AMI declined from 34,084 in 1994 to 19,015 in 2016 (down by 44.2\%). The number of persons hospitalized for AMI decreased from 22,373 in 1994 to 15,419 in 2016 (down by $31.1 \%$ ), with a continuous decrease being interrupted only in 2003 and 2004 by a mild temporary increase. The standardized AMI incidence rate per 100,000 inhabitants European standard population, ESP) fell from 473.2 in 1994 to 192.7 in 2016 (decrease of $59.3 \%$ ), and the standardized rate of hospitalized persons from 299.2 to 154.1 (decrease of $48.5 \%$ ). The proportion of men was higher in AMI incidence as well as in patients hospitalized for AMI and slightly increasing. The mean age was significantly higher in hospitalized women than men, and increased in both sexes (Table 1). AMI incidence and number of persons hospitalized decreased during 1994-2016 in all age groups. The decrease was most pronounced in the age group 0-49 years, and least in the age group $80+$, where the decrease in the number of hospitalized persons was only $5.8 \%$ (Table 2 ).

The total number of reinfarctions per year showed an upward trend to 2004, but did not change substantially in the ensuing years (Table 3 ). The proportion of reinfarctions within the total number of AMI treated per year continued to rise, but they tended to happen later after the first event: e.g. 1997 vs. 2015 . Reinfarction within one year occurred in $3.8 \%$ and $2.4 \%$, respectively.

\section{Trends in AMI mortality and fatality}

Total AMI mortality showed a pronounced decrease: 14,834 AMI deaths in 1994 and only 4,673 in 2016 (down by $68.5 \%$ ). The standardized AMI-related mortality rate per 100,000 inhabitants (ESP) fell from 219.9 to 50.3 (down by $77.1 \%$ ). The mortality of patients hospitalized for AMI decreased from 3,794 deaths in 1994 to 1,137 deaths in 2016 (a decrease of 70\%); this was due to a lower number of AMI patients admitted for treatment and case fatality decreasing from $17 \%$ to $7.5 \%$ (down by $55.4 \%$ ). There was a larger proportion of men among those deceased from AMI; during the analysed period, the mean age of the deceased rose in both sexes (Table 1). Between the years 1994 and 2016, the number of those deceased 


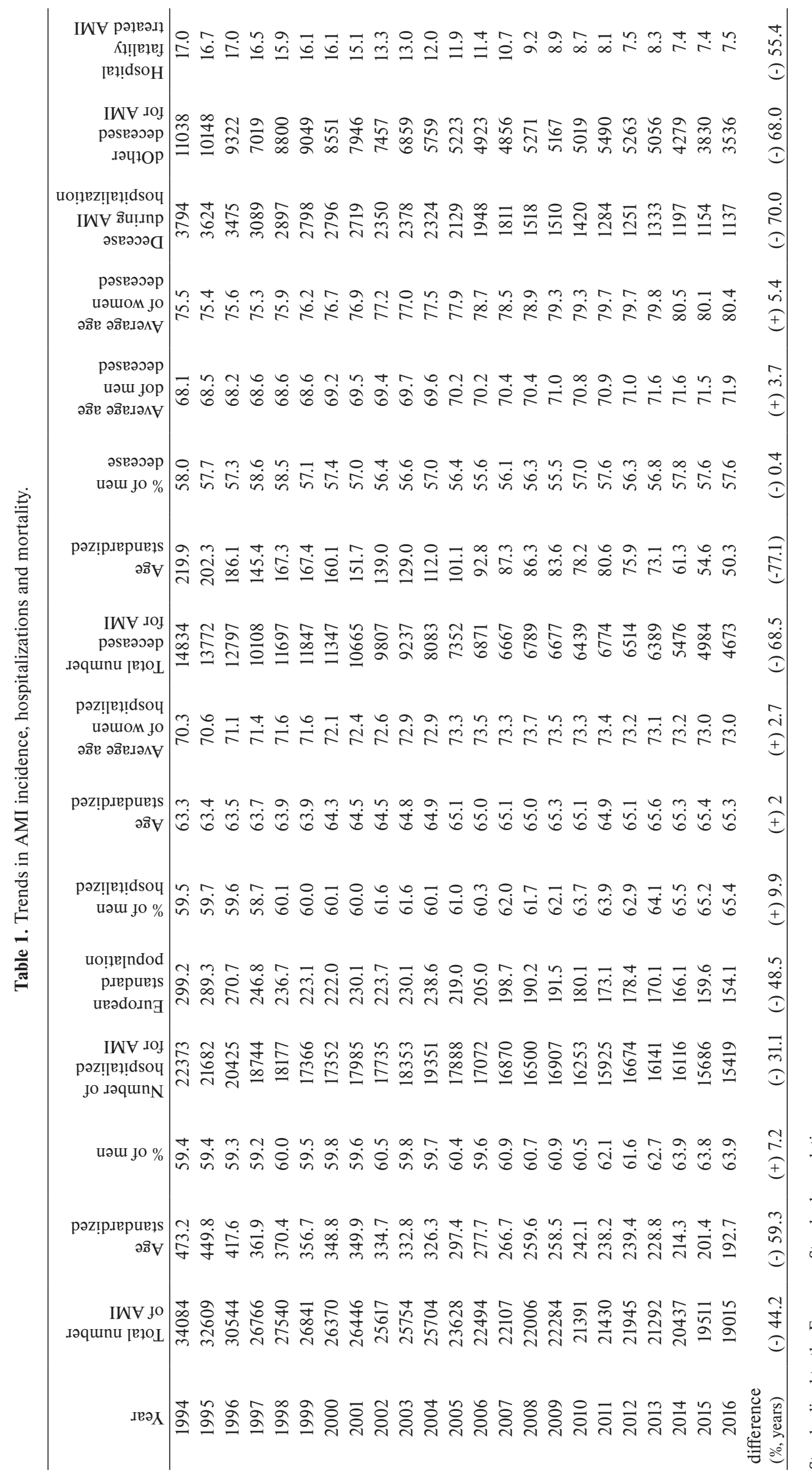




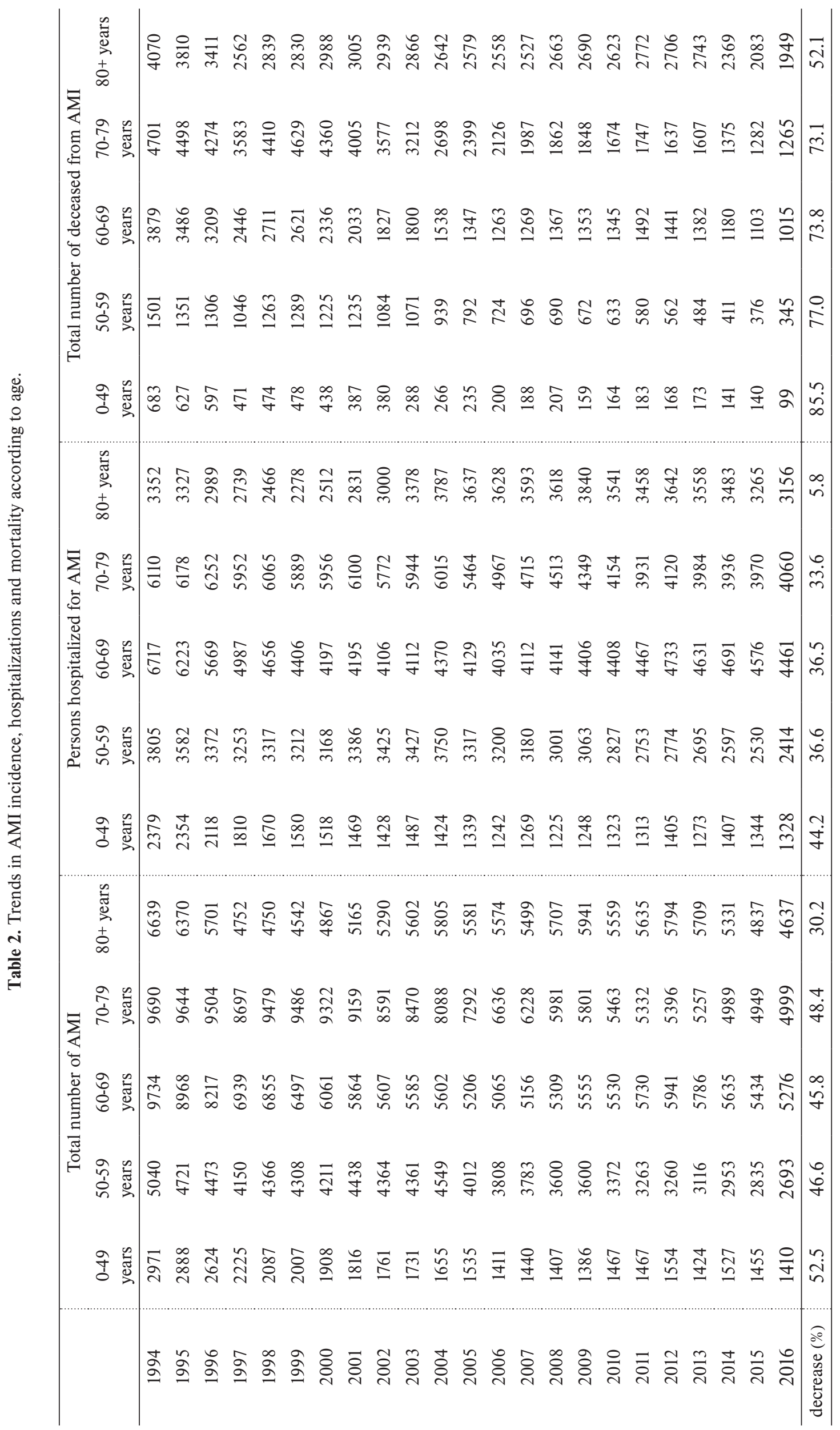


Table 3. Reinfarctions in patients hospitalized for AMI 1994-2016.

\begin{tabular}{|c|c|c|c|c|c|c|c|c|}
\hline \multirow[b]{2}{*}{ Year* } & \multirow[b]{2}{*}{$\begin{array}{l}\text { No of pri- } \\
\text { mary AMI }\end{array}$} & \multirow[b]{2}{*}{$\begin{array}{l}\text { No of } \\
\text { reinfarctions }\end{array}$} & \multirow{2}{*}{$\begin{array}{c}\text { Share of } \\
\text { reinfarctions } \\
(\%)\end{array}$} & \multicolumn{5}{|c|}{ Share of patients in whom in a given period reinfarction occured } \\
\hline & & & & $\begin{array}{c}\text { up to } \\
1 \text { year (\%) }\end{array}$ & $\begin{array}{c}\text { up to } 2 \text { years } \\
(\%)\end{array}$ & $\begin{array}{c}\text { up to } 3 \text { years } \\
(\%)\end{array}$ & $\begin{array}{c}\text { up to } 4 \text { years } \\
(\%)\end{array}$ & $\begin{array}{c}\text { up to } 5 \text { years } \\
(\%)\end{array}$ \\
\hline 1994 & - & - & - & - & - & - & - & - \\
\hline 1995 & - & - & - & - & - & - & - & - \\
\hline 1996 & - & - & - & - & - & - & - & - \\
\hline 1997 & 17198 & 1964 & 10.2 & $3.8 \%$ & 5.6 & 7.0 & 8.2 & 9.4 \\
\hline 1998 & 16738 & 1845 & 9.9 & $3.8 \%$ & 5.8 & 6.9 & 8.0 & 8.9 \\
\hline 1999 & 15752 & 1978 & 11.2 & $3.6 \%$ & 5.5 & 6.6 & 7.6 & 8.7 \\
\hline 2000 & 15678 & 2064 & 11.6 & $3.8 \%$ & 5.5 & 6.8 & 7.9 & 8.8 \\
\hline 2001 & 16138 & 2246 & 12.2 & $3.8 \%$ & 5.3 & 6.5 & 7.7 & 8.5 \\
\hline 2002 & 15770 & 2349 & 13.0 & $3.9 \%$ & 5.4 & 6.4 & 7.4 & 8.3 \\
\hline 2003 & 16257 & 2533 & 13.5 & $4.0 \%$ & 5.4 & 6.5 & 7.3 & 8.2 \\
\hline 2004 & 17134 & 2684 & 13.5 & $3.8 \%$ & 5.2 & 6.1 & 6.9 & 7.6 \\
\hline 2005 & 15673 & 2549 & 14.0 & $3.3 \%$ & 4.8 & 5.8 & 6.7 & 7.4 \\
\hline 2006 & 14892 & 2503 & 14.4 & $3.3 \%$ & 4.6 & 5.6 & 6.5 & 7.2 \\
\hline 2007 & 14711 & 2503 & 14.5 & $3.4 \%$ & 4.9 & 6.1 & 7.0 & 7.8 \\
\hline 2008 & 14350 & 2526 & 15.0 & $3.7 \%$ & 5.1 & 6.1 & 6.9 & 7.7 \\
\hline 2009 & 14530 & 2712 & 15.7 & $3.6 \%$ & 4.6 & 5.7 & 6.6 & 7.4 \\
\hline 2010 & 13883 & 2650 & 16.0 & $3.1 \%$ & 4.6 & 5.6 & 6.4 & 7.2 \\
\hline 2011 & 13705 & 2490 & 15.4 & $3.2 \%$ & 4.6 & 5.6 & 6.5 & 7.2 \\
\hline 2012 & 14272 & 2671 & 15.8 & $2.9 \%$ & 4.3 & 5.3 & 6.3 & - \\
\hline 2013 & 13702 & 2681 & 16.4 & $2.9 \%$ & 4.2 & 5.3 & - & - \\
\hline 2014 & 13743 & 2683 & 16.3 & $2.9 \%$ & 4.1 & - & - & - \\
\hline 2015 & 13299 & 2601 & 16.4 & $2.4 \%$ & - & - & & - \\
\hline 2016 & 12960 & 2443 & 15.9 & - & - & - & - & - \\
\hline
\end{tabular}

* Only data for period 1997-2016 evaluated. Data from 1994-1996 we used for assessment wheather the new cases are primary AMI or reinfarction. As reinfarction we considered a new hospitalization for AMI started at least 30 days after the end of previous AMI hospitalization.

Source: National Register of Hospitalizations 1994-2016

from AMI declined in all age groups. The decrease was most pronounced in the age group 0-49 years (by $85.5 \%$ !), and least in the age group $80+$ (Table 2).

The number of persons dying of AMI outside hospital (at home, at work, in public places or during transportation to hospital) or dying of AMI accidentally in hospital establishments, while not being treated for AMI, decreased from 11,038 in 1994 to 3,536 in 2016 (a decrease of $68 \%$ - nearly the same as in the "treated" segment). This may be due to the decreasing AMI incidence and fatality (Table 1).

\section{Trends in subsequent mortality after AMI}

The prognosis of patients experiencing an AMI also improved in the 1997-2016 period. The total death rate within one month from the beginning of the first hospitalization for AMI decreased from 16.1 to $9.7 \%$, one-year total mortality from 25.1 to $17.9 \%$, and five-year total mortality from 41.7 to $34 \%$. Even more prononouced was the decrease in subsequent CV mortality: one-month mortality from 15.1 to $8.6 \%$, one-year mortality from 22.3 to $14.2 \%$, and five-year mortality from 34.1 to $23.6 \%$ (Table 4). While, during the analysed period, CV disease and CHD in particular remained the prevalent causes of subsequent death, the relative proportion of other causes of death increased. The rate of subsequent mortality after AMI was higher in women than in men; however, the difference disappeared after adjustment for age. Acute and subsequent mortality rates of patients over 75 years of age were about four times those of patients younger than 65 years.

\section{DISCUSSION}

Our study presents the nationwide trends in the incidence, treatment, fatality and subsequent mortality of AMI in the Czech Republic in the 1994-2016 period. Unlike several studies focusing solely on the ST-segment elevation myocardial infarction (STEMI) (ref. ${ }^{1,21,22}$ ) or other specific AMI subpopulations ${ }^{6}$, we analysed the longterm trends in both STEMI and non STEMI, both in patients hospitalized for AMI and in the general population.

The annual incidence of AMI decreased rapidly during 1994-1997, to slow down thereafter. The number of persons hospitalized for AMI followed a similar course. The decrease was most pronounced in the age group 0-49 years, and least pronouced in the age group $80+$. The incidence of AMI as well as the number of patients hospitalized per year are still higher than in most Western 
Table 4. Long term mortality after the first AMI.

Death from any cause (\%)

\begin{tabular}{lcccc}
\hline & $1997-2001$ & $2002-2006$ & $2007-2011$ & $2012-2016$ \\
\hline 1 month & 16.1 & 13.8 & 11.5 & 9.7 \\
1 year & 25.1 & 23.1 & 20.7 & 17.9 \\
3 years & 34.3 & 32.0 & 29.7 & 26.5 \\
5 years & 41.7 & 39.3 & 37.1 & 34.0 \\
\hline
\end{tabular}

\begin{tabular}{lcccc} 
Death from cardiovascular cause (\%) \\
\hline & $1997-2001$ & $2002-2006$ & $2007-2011$ & $2012-2016$ \\
\hline 1 month & 15.1 & 12.6 & 10.3 & 8.6 \\
1 year & 22.3 & 19.6 & 17.1 & 14.2 \\
3 years & 28.9 & 25.6 & 22.9 & 19.3 \\
5 years & 34.1 & 30.4 & 27.4 & 23.6 \\
\hline
\end{tabular}

European countries, but lower than, e.g., in neighbouring Poland ${ }^{9}$. As a consequence of the decreasing AMI incidence and fatality, overall AMI mortality tended to decline throughout the analysed period. The decrease in AMI mortality was most pronounced in the younger and middle age category (up to 59 years). As the rates of mortality from AMI were very high in this age group in pre-1990 Czechoslovakia, this mortality decline is of particular value. Quite surprisingly, the mortality decrease was nearly the same in patients hospitalized and treated for AMI as well as in those not treated - by $68.5 \%$ in total, which is a considerably greater decrease than the decrese in all-cause and CV mortality in the Czech population in that period (by $47 \%$ and $61 \%$, respectively). Inhospital AMI fatality dropped by $55.4 \%$ and is currently lower than the European average ${ }^{23}$. The total number of reinfarctions per year was increasing until 2004 not to change substantially afterwards. Reinfarctions tended to occur later after the first AMI and their share on all AMI admitted to hospital treatment reached $16.4 \%$, a figure lower than that reported, e.g., in Olmsted county study $(28 \%)\left(\right.$ ref. $\left.^{5}\right)$. We used a run-in period, which may actually underestimate the recurrence rate at the start of period we analysed, but this is compensated as our data cover a longer period of time.

Treatment of AMI, especially in-hospital treatment, made impressive advances in the Czech Republic in the period we followed. The interval from the onset of AMI symptoms to hospital admission and interventional procedure shortened. The proportions of successful resuscitation and those of patient survival after resuscitation increased, especially so in recent years and after the introduction of specialized post-resuscitation care and centres. The number of direct (emergent) PCIs rose from 104 in 1995 to 6,958 in 2014 (32.3\% of all PCIs performed). While the number of direct PCIs followed an upward trajectory, that of all PCIs per year did not increase after 2006. As shown in our earlier publications, increasing numbers of patients were being treated by antiplatelets, ACE inhibitors, beta-blockers and statins during and after hospitalization for AMI (ref. ${ }^{19,20}$ ).

Regarding secondary prevention of AMI in the 1995-
2016 period, use of beta-blockers and ACE inhibitors or sartans, apparently in the prevention of left vetricular (LV) remodelling, medical treatment with antiplatelet drugs, as well as medical treatment of hypertension and hyperlipidemia became much more widespread and has remained stable in recent years. In men and women total cholesterol and LDL-cholesterol levels decreased intensively and there was a less consistent decrease in average blood pressure and improved arterial hypertension control. However, mostly due to insufficient titration of medicaments to optimaly effective dosage, about half of patients in secondary AMI prevention still do not meet the goals specified by the current guidelines. There has been a reduction in smoking, but the prevalence of obesity, central obesity, sedentary lifestyle and diabetes has increased considerably ${ }^{19}$.

As for general population and primary CV prevention, smoking rates decreased only in men while cholesterol and LDL-cholesterol levels have dropped markedly in both sexes. The decrease in average blood pressure and better control of arterial hypertension were less pronounced ${ }^{19,24}$. There was a substantial increase in evidencebased use of cardiac drugs. Given their risk profile, some patients, were being treated by antiplatelet drugs (mostly acetylsalicylic acid), beta-blockers, ACE inhibitors, sartans or lipid-lowering drugs even before experiencing an AMI.

Particularly intriguing is the mortality in the subgroup of patients dying from AMI without being admitted or treated for this diagnosis. Over the 1994-2016 period, no significant difference in the decrease in mortality in this subgroup (down by $68 \%$ ), compared with patients admitted and treated for AMI (down by 70\%) was observed. This can be explained both by the decreasing incidence of AMI, and the general drop in AMI-related fatality. We can presume, that improvements in primary and secondary CHD prevention may be pivotal.

Due to urgent revascularizations and comprehensive medical care, more patients survive AMI with minor myocardial injury and LV remodelling ${ }^{25}$. Given the progress in subsequent medical care, and drug therapy in particular, these developments have translated into adecrease 
in subsequent mortality. At present, long-term post-AMI mortality in the Czech Republic is even lower than the European average ${ }^{23}$.

Periods of rapid decrease and slower or even zero decrease in AMI incidence and mortality, at least in some age strata, have been reported in several countries ${ }^{10,22}$. In this context, three periods can be distinguished in the Czech Republic: first, simultaneous rapid decrease of AMI incidence and mortality (1994-1997), second, slow decrease in AMI incidence and mortality (1998-2004), followed by a further decrease in AMI incidence and a more pronounced reduction in AMI mortality (20062016). The fall in the first period was driven nearly exclusively by lifestyle changes after 1989, particularly in nutrition; in the second phase by progress in cardiovascular treatments ${ }^{20}$, whereas the third phase can probably be explained by continuing progress in interventional cardiology, acute coronary care and medical treatment, and slightly better control of some lifestyle risk factors.

The length of hospitalization for AMI shortened considerably during the period followed. This results, partly because of lack of time, in insufficient education of patients towards positive changes in lifestyle and adherence to further treatment. Cardiovascular rehabilitation is carried out on a minority of patients while traditional spa-based cardiac rehabilitation programs are almost exclusively available to patients after cardiac surgery procedures only.

\section{Strengths and limitations}

The advantage of our study is the presentation and analysis of nationwide, long-term trends and comparison with repeated cross-sectional studies of secondary CHD prevention. The limitations include absence of personalised data on in-hospital (except interventional) and subsequent health care, as these are not recorded in the current registers. Mortality data were not recorded separately for patients with STEMI and non STEMI. A variable quality of data recorded in specialized interventional cardiac centres and other hospitals can be presumed as well as less accurate data on patients dying outside hospital.

\section{CONCLUSION}

In the Czech Republic, 1994-2016, there was an impressive decrease in AMI incidence and mortality and a decrese in long-term mortality after AMI as well. Should this positive trend continue, further improvement in primary and secondary CV prevention is needed.

Acknowledgement: Authors would like to thank Skans Victoria Airey and René Prahl, MSc. for their help with English text of this article. The author(s) disclosed receipt of the following financial support for the research, authorship, and/or publication of this article: JB, OM and JBjun were supported through a research grant from the Medical Research Agency, Ministry of Health of the Czech Republic (Grant No 17-29520A).

Authors'contribution: JB, JJ, JB jr: contributed to the conception or design of the work; JB, OM, JJ, MZ, JB jr: contributed to the aquisition, analysis, or interpretation of data; JB: drafted the manuscript; OM, JJ, MZ, JB jr: critically revised the manuscript; All authors gave final approval and agree to be accountable for all aspects of the work ensuring integrity and accuracy.

Conflict of interest statement: None declared.

Ethics: This project was carried out in accordance with the current rules of ethics and legislation. No additional actions involving the persons evaluated in this study were undertaken.

\section{REFERENCES}

1. Bruthans J. Kardiovaskulární onemocnění v České republice v letech 1965-2014 a faktory, které je ovlivňovaly. (Cardiovascular diseases in the Czech Republic 1965-2014 and influencing factors). Praha: Gasset; 2017.

2. Szummer K, Wallentin L, Lindhagen L, Alfredsson J, Erlinge D, Held C, James S, Kellerth T, Lindahl B, Ravn-Fischer A, Rydberg E, Yndigegn T, Jernberg T. Improvedoutcomes in patientswith ST-elevationmyocar dialinfarctionduringthe last 20 years are related to implementationofevidence-basedtreatments: experiences fromthe SWEDEHEART registry 1995-2014. EurHeart J 2017;38:3056-65.

3. Schmidt M, Jacobsen JB, Lash TL, Botker HE, Sorensen HT. 25 years trends in first hospitalization for acute myocardial infarction, subsequent short and long term mortality, and the prognostic impact of sex and comorbidity: a Danish nationwide cohort study. BMJ 2012;344:e356.

4. Degano IR, Salomaa V, Veronesi G, Ferrieres J, Kirchberger I, Laks T, Havulinna AS, Ruidavets JB, Ferrario MM, Meisinger C, Elosua R, Marrugat J. Acute Myocardial Infarction Trends in Europe Study Investigators. Twenty-five-years trends in myocardial infarction attack and mortality rates, and case fatality, in six European populations. Heart 2015;101:1413-21.

5. Gerber Y, Weston SA, Jiang R, Roger VL. The changing epidemiology of myocardial infarction in Olmsted county, Minnesota, 1995-2012: Trends in myocardial infarction incidence and recurrence. Am J Med 2015;128:144-51.

6. Nauta ST, Deckers JW, Akkerhuis KM, van Dornburg RT. Short- and long- term mortality after myocardial infarction in patients with and without diabetes. Diabetes Care 2012;35:2043-7.

7. Bata IR, Gregor RD, Wolf HK, Brownell B. Trends in five-year survival of patients discharged after acute myocardial infarction. Can J Cardiol 2006;22:399-404

8. Smolina K, Wrigh FL, Rayner M, Goldacre MJ. Longterm survival and recurrence after acute myocardial infarction in England, 2004-2010. Circulation: Cardiovascular Quality and Outcomes 2012;5:532-40.

9. Gierlotka M, Zdrojewski T, Wojtyniak B, Polonski L, Stokwiszewski J, Gasior M, Kozerkiewicz A, Kalarus Z, Wierucki L, Chlebus K, Zembala M, Wisocki M, Opolski G. Incidence, treatment, in-hospital and oneyear outcomes of acute myocardial infarction in Poland in 20092012 - nationwide diabase AMI-PL. Kardiol Pol 2015;73(3):142-58. doi:10.5603/KP.a2014.0213.

10. Sulo G, Igland J, Vollset SE, Ebbing M, Egeland GM, Ariansen I, Tell GS. Trends in incident acute myocardial infarction in Norway: An updated analysis to 2014 using national data from the CVDNOR project. Eur J Prev Cardiol 2018;25:1031-9.

11. Grey C, Jackson R, Wells S, Wu B, Poppe K, White H, Chan WC, Kerr AJ. First and recurrent ischaemic heart disease events continue to decline in New Zealand, 2005-2015. Heart 2018;104(1):51-7. doi: 10.1136/heartjnl-2017-311613

12. Freisinger E, Fuerstenberg T, Malyar NM, Wellman J, Keil U, Breithardt $\mathrm{G}$, Reinecke H. German nationwide data on current trends and management of acute myocardial infarction: discrepancies between trials and real-life. Eur Heart J 2014;35:979-88. 
13. Yeh RW, Sidney S, Chandra M, Sorel M, Selvy JV, Go AS. Population trends in the incidence and outcomes of acute myocardial infarction. N Engl J Med 2010;362:2155-65.

14. Koopman C, Bots ML, van Oeffelen AA, van Dis I, Verschuren WM Engelfriet PM, Capewell S, Vartjes I. Population trends and inequalities in incidence and short term outcome of acute myocardial infarction between 1998 and 2007. Int J Cardiol 2013;168:993-8.

15. Bernatová M. Hospitalizovaní a zemřelí na infarkt myokardu v ČR v letech 1986-2000. Aktuální informace ÚZIS ČR Č. 20, 2002. (In Czech)

16. Bernatová M. Hospitalizovaní a zemřelí na infarkt myokardu v ČR v letech 2001-2002. Aktuální informace ÚZIS ČR č. 13, 2004. (In Czech)

17. Zvolský M. Nemocnost a úmrtnost na ischemické nemoci srdeční v ČR v letech 2003-2010, aktualizace. Aktuální informace ÚZIS ČR č. 24, 2012. (In Czech)

18. Thygesen K, Alpert JF, Jaffe AS, Simoons ML,Chaitman BR. Third universal definition of myocardial infarction. Eur Heart J 2012;33:2551 67.

19. Mayer $O$, Bruthans J, Rychecká $M$. Změny úrovně sekundární prevence ischemické choroby srdeční mezi lety 1995 a 2017. Porovnání studií EUROASPIRE I, II, III, IV a V u českých pacientů. (The changes in secondary CHD prevention between 1995 and 2017 in the Czech patients) Vnitř Lék 2018;64:1190-9. (In Czech)
20. Bruthans J, Cífková R, Lánská V, O’Flaherty M, Critchley JA, Holub J, Jansky P, Zvárová J, Capewell S. Explaining the decline in coronary heart disease mortality in the Czech Republic between 1985 and 2007. Eur J Prev Cardiol 2012;21:829-39.

21. Puymirat E, Simon T, Steg PG, Schiele F, Guéret $P$, Blanchard D, Khalife K, Goldstein P, Cattan S, Vaur L, Cambou JP, FerriereJ, Danchin N. Association of changes of clinical characteristics and management with improvement in survival among patients with ST-elevation myocardial infarction. JAMA 2012;308:998-1006.

22. Eagle KA, Nallamothu BK, Mehta RH, Granger CB, Steg PG, Van de Werf F, López-Sendón J, Goodman SG, Quill A, Fox KA. Trends in acute reperfusion therapy for ST-segment elevation myocardial infarction from 1999 to 2006: we are getting better but we have got a long way to go. Eur Heart J 2008;29:609-17.

23. Townsend N, Wilson L, Bhatnagar P, Wickramasinghe K, Rayner M, Nichols M. Cardiovascular disease in Europe: epidemiological update 2016. Eur Heart J 2016;37:3232-45.

24. Cífková R, Škodová Z, Bruthans J, Adámková V, Jozífová $M$, Galovcová M, Wohlfart P, Krajčoviechová A, Poledne R, Stávek $P$, Lánská V. Longitudinal trends in major cardiovascular risk factors in the Czech population between 1985 and 2007/8. Atherosclerosis 2010;211:676-81.

25. Cokkinos DV, Belogianneas Ch. Left ventricular remodelling: a problem in search of solutions. European Cardiology Review 2016;11(1): 29-35. 